\title{
Foreward to Proceedings from the Budapest Meeting
}

Although the scientific value of Proceedings cannot compare with original work or review articles published in peer reviewed journals, they do provide a contemporary window on a particular science. Because the $\mathrm{Bu}-$ dapest Satellite Symposium on CRPS is the 12th Anniversary of the original meeting at Schloss Rettershof in 1988, the clinical and scientific reports presented at this meeting actually represent an important account on progress that has been made since that time. Also, due to the imminent 2nd IASP Research Symposium held in Cardiff on October 5-7, 2000, considerable urgency to publish these papers necessitated their editorial review by the Proceedings editors and without the normal participation of the individual authors. It was, there- fore, felt important to publish these Proceedings with their inherent flaws of syntax, expression and grammar in the interest of making the information available to the widest clinical and scientific audience, and in as timely a manner possible. For these reasons, the Proceedings editors are indebted to the Editor-in-Chief of the publication journal.

M. Stanton-Hicks, MB:BS, Dr. med. Vice Chairman, Division of Anesthesiology, Pain Management and Research The Cleveland Clinic Foundation Cleveland, Ohio, USA 